\title{
ENHANCED DIRECT CONVERTER WITH MINIMUM SWITCHING DEVICES AND VARIABLE CAPACITOR
}

The paper deals with a single-leg direct (matrix) converter with minimum switching devices and enhancements for improving current THD and phase advancing with the use of variable (switched) capacitors. This converter supplies single-phase induction motor (SPIM). Due to strongly non-harmonic phase voltages, an additional circuit should be used, so that phase-currents can be nearly harmonic. Simulations are done under both resistive-inductive load and motoric load. Speed control was realized using vector control with current controlled pulse-width-modulation (hysteresis regulator). Verification of such a drive system was done using dSpace environment. Preliminary results are given in the paper.

Keywords: one-leg matrix converter, bi-directional switch, single-phase induction motor - SPIM, speed control, pulse width modulation, switched capacitor

\section{Introduction}

The Single-phase induction motor - SPIM is widely used in a range of applications such as residential blowers, pumps, and compressors operated under fixed frequency. Using variable speed operation, this drive brings possible energy and money saving for consumers [1-3]. The motor can be supplied either from two single-phase or one three-phase VSI inverter [2, 4]. The matrix converter $(\mathrm{MxC})$ topology has become well known after substitution of thyristor-devices in cyclo-converters by switchedoff elements acting in the high-frequency range, in 70-80-years [5-7]. The MxC replaces two energy conversion by one energy conversion only because within the converter there is not an energy storage element. Since classical electric conversion uses DC-link converters with somewhat large smoothing capacitors, direct MxC operates without a DC-link circuit. One of the main advantages of that is unity power factor on its input side. Another advantage is that this converter generally offers sinusoidal input and output, harmonics quantity and bi-directional energy flow. To save some amount of power switching elements, it is possible to use the one-leg connection of the converters. The basic configuration of single-leg $\mathrm{MxC}$ was derived from single-leg voltage source inverter [1], [4], and for the first time was published in 2015, [5] with analysis and modeling [8]. Preliminary comparison of a SPIM Drive Fed by VSI and MxC with Option of Speed Reduction has been made in [9]. The proposed system, in relation to the conventional system currently used, reduces the number of power switching elements of the converter.

\section{Single leg matrix converter}

There are basically two different topologies of single-leg matrix converter derived from topologies of single-leg voltage source inverter [5], [9], Figure 1 and Figure 3. Similarly to singleleg voltage source inverter, single-leg matrix converter also works with two operation modes.

\subsection{Topology of a single leg $\mathrm{MxC}$ fed single phase induction motor for full speed operation}

Basic connection is given in Figure 1. Denotes R1, L1 and R2, L2 represent the phase windings of the motor.

In full speed regime of operation, the main phase of IM is supplied by one half of the main voltage directly; therefore, the motor should be designed for that voltage. The auxiliary phase is supplied by one-leg matrix converter creating voltage with phase shift by 90 degrees against voltage of the main phase.

The first operation mode can be called "Full speed operation." The main phase is fed by voltage source $\mathrm{U}_{\mathrm{AC}} / 2$ and auxiliary phase is fed by a single leg MxC. As in the single leg, VSI using MxC is also necessary to sense phase of AC voltage source and ensure $90^{\circ}$ phase shift for auxiliary phase.

It is necessary to be aware of that supply voltage for the auxiliary phase is strongly non-harmonic, Figure 2.

\footnotetext{
* Roman Konarik, Michal Prazenica, Slavomir Kascak

Department of Mechatronics and Electronics, University of Zilina, Zilina, Slovakia

E-mail: roman.konarik@fel.uniza.sk
} 


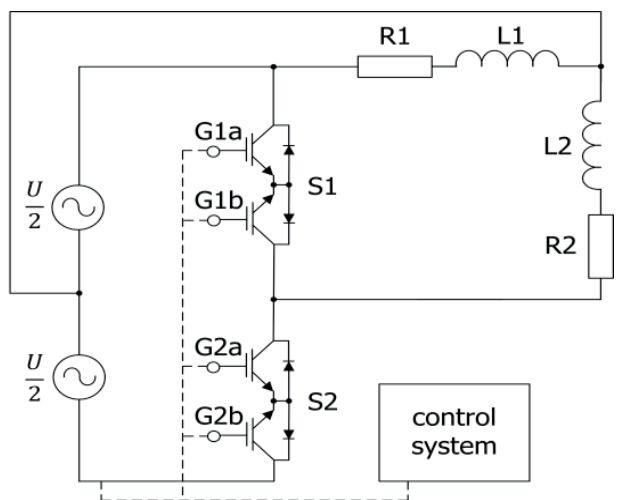

Figure 1 Single leg matrix converter topology for full speed operation

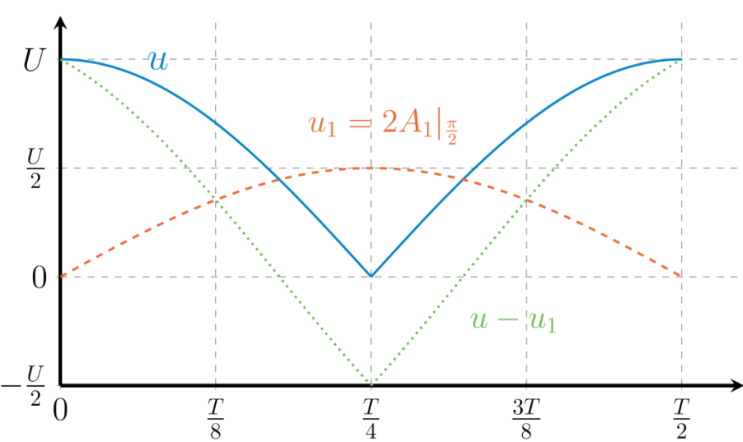

Figure 2 Supply voltage for auxiliary phase and its fundamental harmonic [8]

As the magnitude of fundamental harmonic is equal to one half of the network magnitude, the induction motor should be designed to that value of supply network voltage.

Besides, it is also important, that total harmonic distortion of the auxiliary phase voltage reaches up to $86 \%$, so the torque of the sum of higher harmonics will permanently brake, and start-up of the motor is practically impossible. Using some control method (e.g., hysteresis CC_PWM) the current shape will be good, but anyway, the value of the auxiliary phase voltage will be always smaller as the nominal one.

\subsection{Topology of a single leg MXC fed single phase induction motor to reduce the speed operation}

The second operation mode is also called "Reduced speed operation." Main and auxiliary phase is fed by single leg MxC, Figure 3. The speed of induction machine is given by the frequency of voltage. The phase shift is ensured by a capacitor connected in series with the auxiliary phase.

Similarly, as in the previous case, waveforms of supply voltages are still strongly non-harmonic ones, Figure 4.

So, it is necessary to accept some measures for improving the voltage and current, respectively, waveforms.

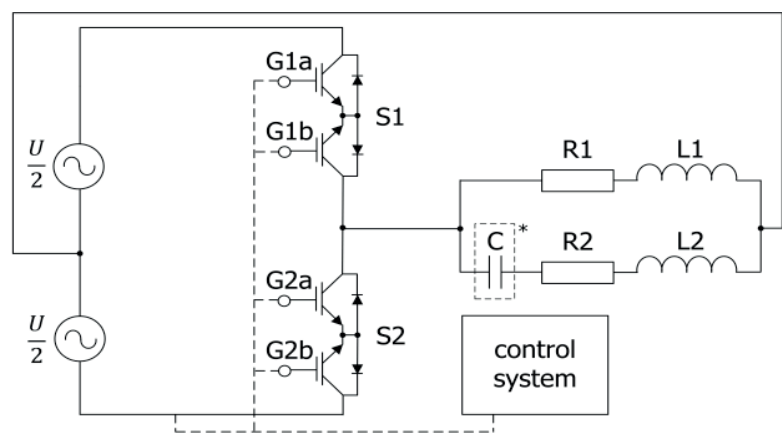

Figure 3 Single leg matrix converter topology for reduced operation

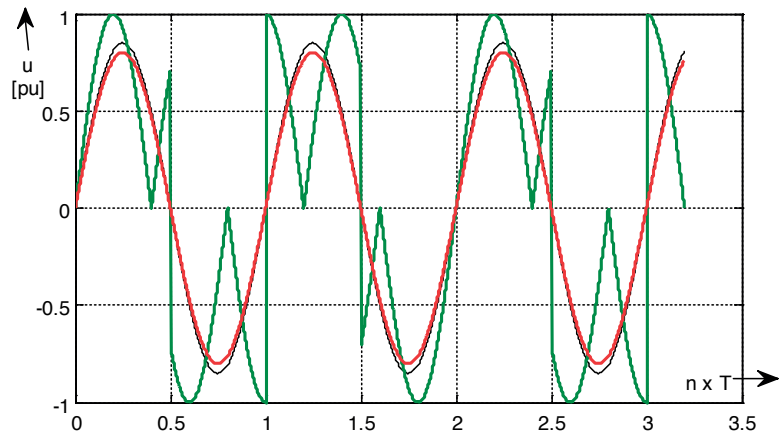

Figure 4 Supply voltage of both phases with its fundamental harmonics in reduced speed regime at $33.33 \mathrm{~Hz}$

\subsection{Using LC filters and switched capacitors for improvement of converter waveforms}

Using resonant $L_{\text {res }} C_{\text {res }}$ filter in main and/or auxiliary phase and designed, e.g., by [10] the current waveform will be acceptable Figure 5 and Figure 6 . The problem, maybe, could be regarding a higher voltage of the resonant capacitor and/or bigger dimensions of the filter element due to relatively smaller resonant frequency.

Another possibility is to use the non-resonant low-pass filter on the output of the converter. Results, as regarding to phase currents, are similar to those of resonant filter, Figure 7 and Figure 8 .

Another problem is that under variable frequency the value of both capacitors, for phase shift and for resonance, should also be variable one. One of the solutions, how to provide this problem, is to use switching capacitors [11, 12]. Anyway, the number of electronic switches will be higher. There is shown acting of switching capacitance for controlled phase shift 90 deg., in Figure 9 and Figure 10. 


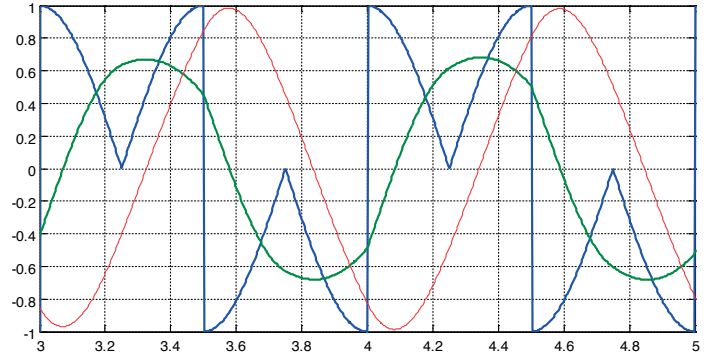

Figure 5 Supply voltage (blue) and current (green) of auxiliary phase, and capacitor voltage (red) at nominal speed, $50 \mathrm{~Hz}$ - without PWM

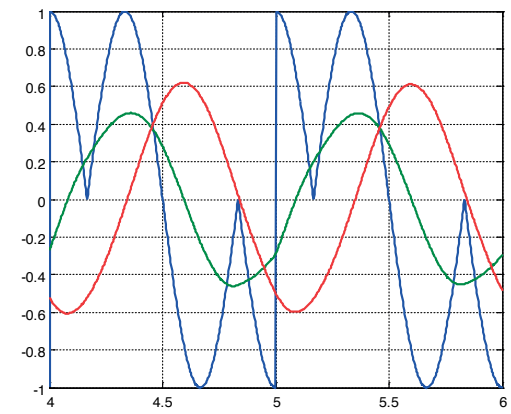

Figure 6 Supply voltage (blue) and current (green) of main and auxiliary phases, and capacitor voltage (red) at reduced speed, $33.33 \mathrm{~Hz}$ - without PWM

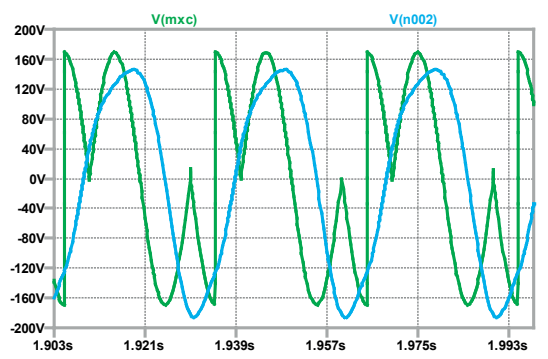

Figure 7 Supply voltage (green) and voltage (blue) of main and auxiliary phases at reduced speed, $33.33 \mathrm{~Hz}$ - without PWM

\section{Single phase induction machine}

\subsection{Model of single phase induction motor}

Model of such a motor is well known [1-4], [11]. So, the electric machine being considered may be described by the following set of ordinary differential equations in the stator reference coordinate frame under the commonly used simplifying assumptions:

$$
\begin{aligned}
& u_{s \alpha}=R_{s \alpha} \cdot i_{s \alpha}+L_{s \alpha} \cdot \frac{d i_{s \alpha}}{d t}+L_{M \alpha} \cdot \frac{d i_{r \alpha}}{d t} \\
& u_{s \beta}=R_{s \beta} \cdot i_{s \beta}+L_{s \beta} \cdot \frac{d i_{s \beta}}{d t}+L_{M \beta} \cdot \frac{d i_{r \beta}}{d t}
\end{aligned}
$$

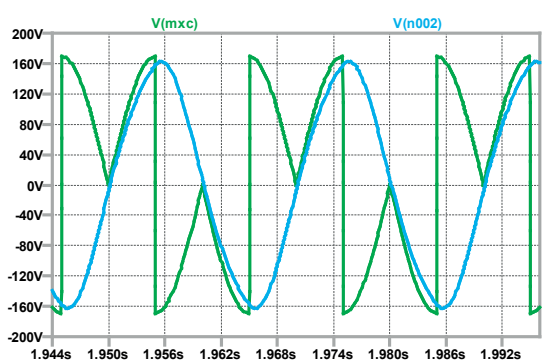

Figure 8 Supply voltage (green) and voltage (blue) of main and auxiliary phases at full speed, $50 \mathrm{~Hz}$ - without PWM
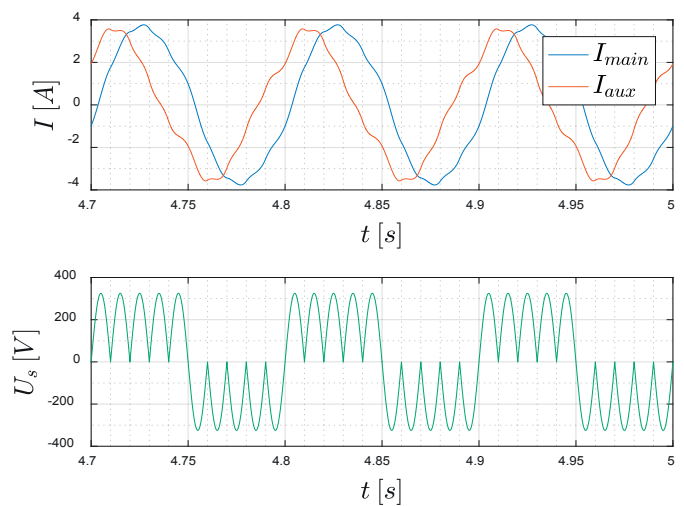

Figure 9 Quadrature currents of single-phase induction motor at $10 \mathrm{~Hz}$
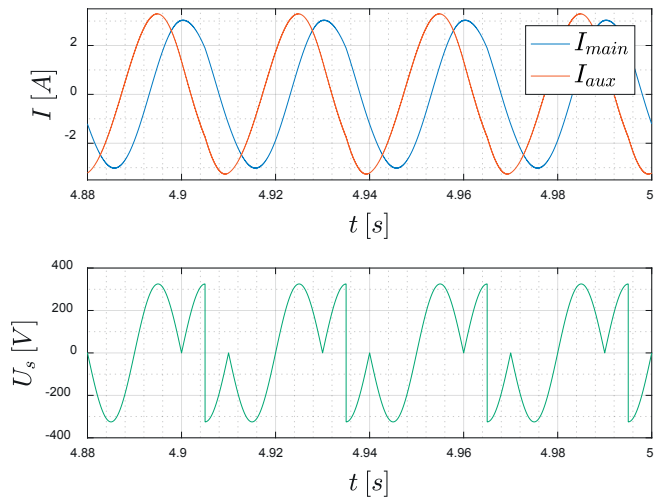

Figure 10 Quadrature currents of single-phase induction motor at $33.33 \mathrm{~Hz}$

$$
\begin{aligned}
& 0=R_{r \alpha} \cdot i_{r \alpha}+L_{s \alpha} \cdot \frac{d i_{r \alpha}}{d t}+L_{M \alpha} \cdot \frac{d i_{M \alpha}}{d t}+ \\
& +\frac{1}{N} \cdot \omega_{m} \cdot\left(L_{r \beta} \cdot i_{r \beta}+L_{M \beta} \cdot i_{s \beta}\right) \\
& 0=R_{r \beta} \cdot i_{r \beta}+L_{r \beta} \cdot \frac{d i_{r \beta}}{d t}+L_{M \beta} \cdot \frac{d i_{s \beta}}{d t}- \\
& -N \cdot \omega_{m} \cdot\left(L_{r \alpha} \cdot i_{r \alpha}+L_{M \alpha} \cdot i_{s \alpha}\right) \\
& T_{e}=p p \cdot\left[N \cdot\left(L_{r \alpha} \cdot i_{r \alpha}+L_{M \alpha} \cdot i_{s \alpha}\right) \cdot i_{r \beta}-\right. \\
& \left.-\frac{1}{N} \cdot\left(L_{r \beta} \cdot i_{r \beta}+L_{M \beta} \cdot i_{s \beta}\right) \cdot i_{r \alpha}\right] \\
& T_{e}=T_{\text {load }}+J \cdot \frac{d \omega_{m}}{d t}
\end{aligned}
$$

where $N$ is the ratio between the effective numbers of turns in the auxiliary and the main stator windings; $\omega_{m}$ - mechanical angular speed, and $p p$ - is the number of pole pairs. 


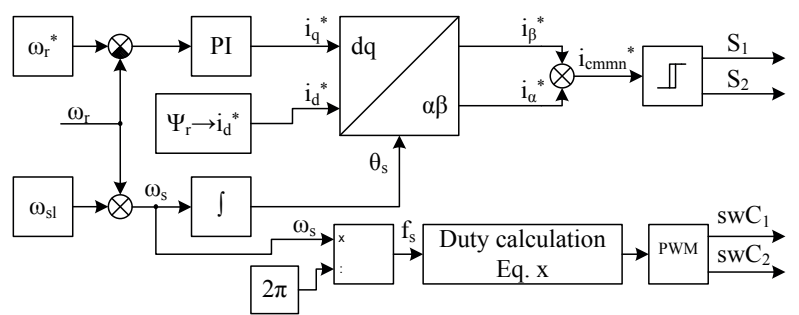

Figure 11 Block scheme of speed control of the drive with single-phase induction motor and single-leg matrix converter

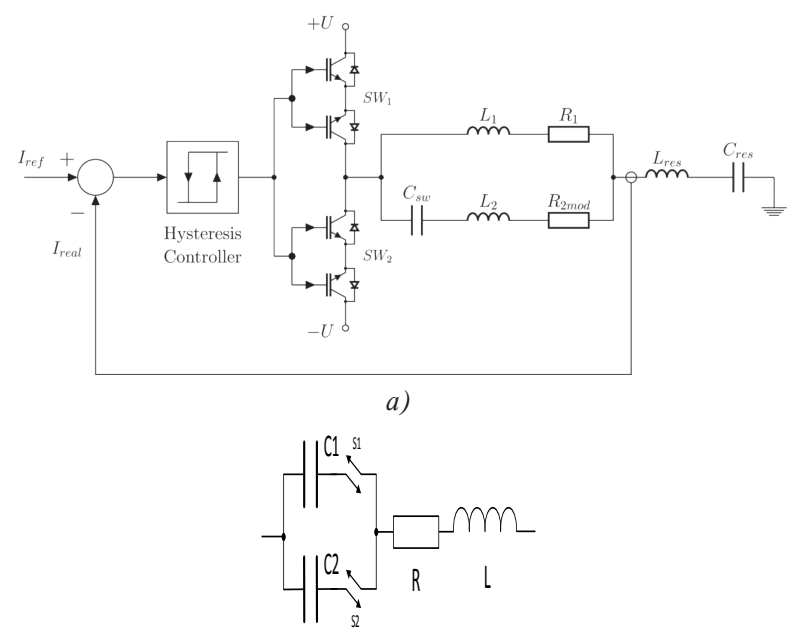

b)

Figure 12 Block scheme: a) CC_PWM (hysteresis) control of the drive,

b) switched capacitor circuit

\subsection{Speed control of a single-phase induction motor fed by single leg MXC}

The basic control schematic is shown in Figure 11.

It deals with common vector control. Moreover, phase-shift of auxiliary phase is controlled by computation of duty cycle for the needed value of the running capacitor.

Current of common phase is controlled by CC_PWM (hysteresis) controller [13, 14], Figure 12.

\section{Modeling and simulations}

All simulations were calculated using the Matlab-Simulink package for source voltage $230 \mathrm{~V}_{\text {RMS }}, 50 \mathrm{~Hz}$ at full speed operation, a calculation step of $1 \mathrm{e}^{-5} \mathrm{sec}$.

Parameters of the single-phase motor:

Stator voltage $230 \mathrm{~V}$

Stator resistance $\mathrm{R}_{\mathrm{s} \alpha}=58.85 \Omega ; \mathrm{R}_{\mathrm{s} \beta}=66.1 \Omega ; \mathrm{R}_{\mathrm{r}}=80 \Omega$

Stator inductance $\mathrm{L}_{\mathrm{sd}}=1.835 \mathrm{H} ; \mathrm{L}_{\mathrm{sq}}=1.64 \mathrm{H}$

Mutual inductance between rotor and stator

$\mathrm{M}_{\text {srd }}=1.74 \mathrm{H} ; \mathrm{M}_{\text {srq }}=1.52 \mathrm{H}$

Moment of inertia $\mathbf{J}=0.0000488 \mathrm{~kg} \cdot \mathrm{m} 2$

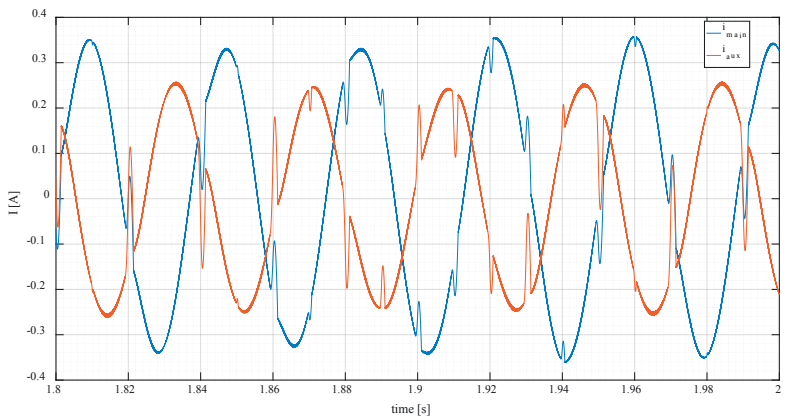

Figure 13 Quadrature currents of main and auxiliary phases main (blue) and auxiliary (red) at reduced speed, $33.33 \mathrm{~Hz}$ - with PWM

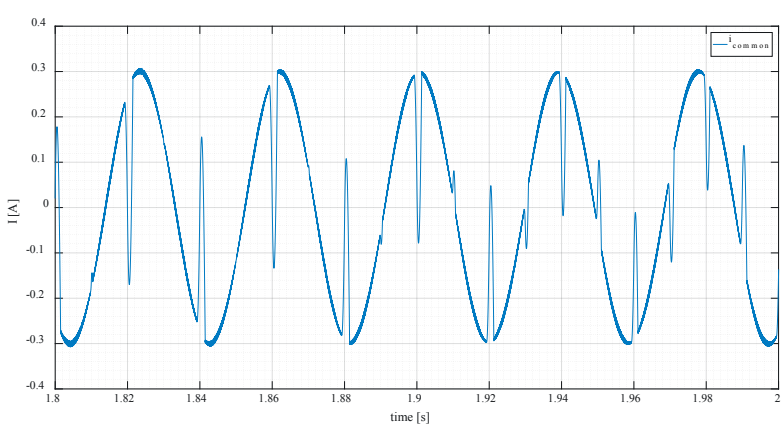

Figure 14 The current of both phases-common phase at reduced speed, $33.33 \mathrm{~Hz}$ - with PWM

Number of pole pairs $\mathrm{pp}=1$;

The capacitance of the capacitor in auxiliary phase $\mathrm{C}=14.6 \mu \mathrm{F}$.

\subsection{Simulations of a single-phase induction motor fed by single leg MxC with PWM only}

Single-phase induction motor was fed by voltage waveform depicted in Figure 5 or Figure 6, respectively. Simulation result of phase currents waveforms are shown in Figure 13.

The current of common phase, i.e., current taking from the network is given in Figure 14.

\subsection{Simulations of a single-phase induction motor fed by single leg $\mathrm{MxC}$ with $\mathrm{PWM}$ and resonant LC filter}

Single-phase induction motor was fed by voltage as above, and the simulation result of both phase currents and common phase current are depicted in Figure 15 and Figure 16 are nearly harmonic ones. 


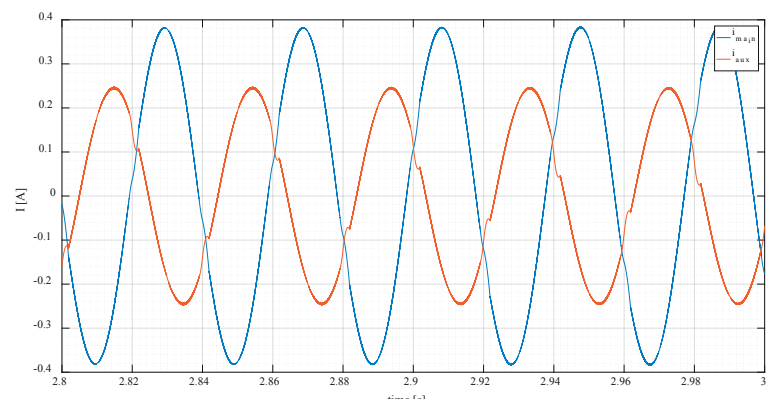

Figure 15 The current of both phases-common phase at reduced speed, $33.33 \mathrm{~Hz}$ - with PWM and resonant LC filter

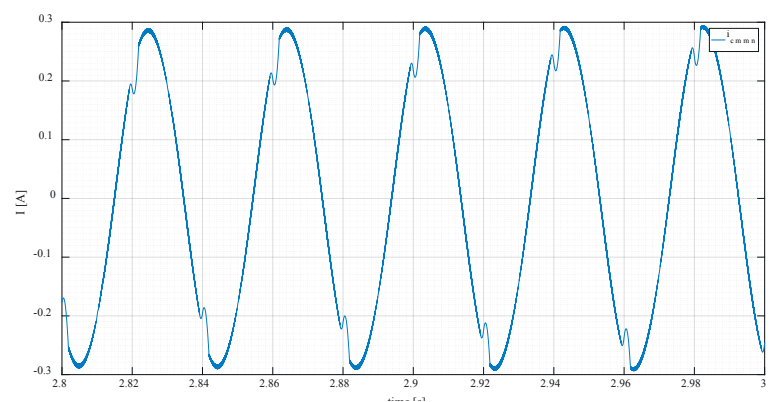

Figure 16 The common current of both phases reduced speed, $33.33 \mathrm{~Hz}$ - with PWM and resonant LC filter
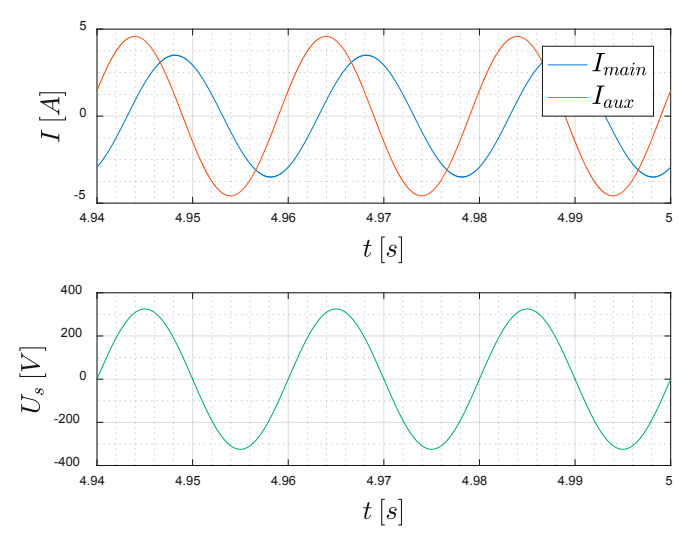

Figure 17 Quadrature currents of main and auxiliary phases main (blue) and auxiliary (red) at full speed, $50 \mathrm{~Hz}$ - without PWM

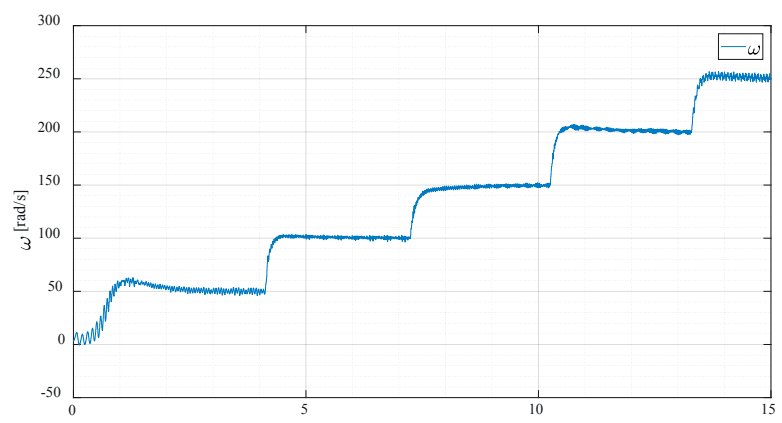

Figure 18 Step changes of angular speed

$(5 \mathrm{kHz})$ are depicted in Figure 20 and the value of the voltage for each capacitor depends on the duty cycle.

In Figure 21 are depicted details of phase current of single phase induction machine. It can be seen in the figures that the currents are almost harmonic.

\section{Conclusion}

The paper brings simulation and experimental result of singlephase motor drive that consists of single-phase induction motor fed by enhanced single leg $\mathrm{MxC}$ with switched capacitors.

Simulations were done with both resistive-inductive load and motoric load. Due to strongly non- harmonic phase voltages the additional circuits were implemented and investigated: resonant LC filter and/or low-pass filter, respectively. Accepting mentioned measures, the phase-currents are nearly harmonic. It is very important from the point of view of the influence of the supply network.

As can be seen in the Figure 14 and Figure 16 respectively, the common phase current taken from the network is nearly sinusoidal with the harmonic time waveform. This is one of the advantages of the described drive system. Another advantage is minimum active switching devices, because the single-leg 


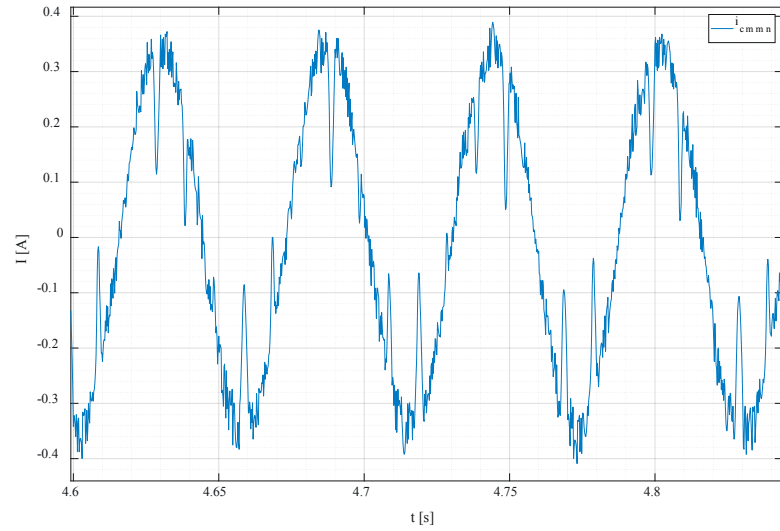

Figure 19 Detail of the common current of main and auxiliary phases

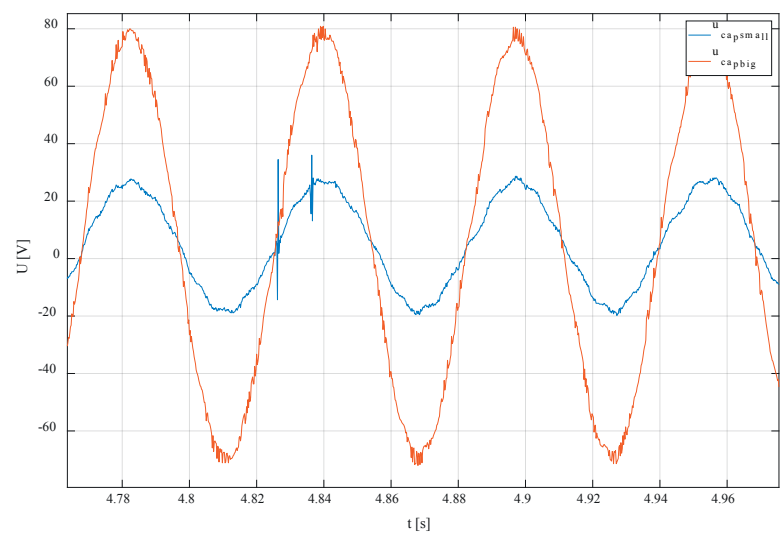

Figure 20 Detail of capacitor voltages: a small capacitor (blue) and

a large capacitor (red) at capacitor switching frequency of $5 \mathrm{kHz}$

matrix converter in basic connection topology needs just two bidirectional switches. But for the demanded vector control it is necessary to use a switched capacitor to maintenance $90 \mathrm{deg}$ phase-shift in whole speed range under a no-load and nominal load of the motor. Application of the switched capacitors brings

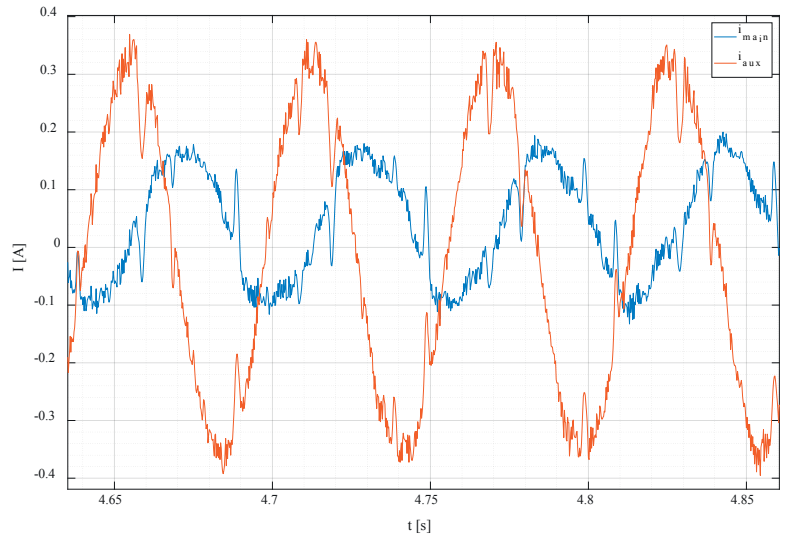

Figure 21 Detail of the currents of main and auxiliary phases main (blue) and auxiliary (red)

the possibility of a wider range of angular speed and improvement of the electromagnetic torque. The switching frequency of the capacitors direct impacts the voltage ripple on the capacitors.

The novelty of the paper is also in speed control that was realized using adapted vector control with current controlled pulse width modulation (hysteresis regulator). Verification of such a drive system was done using dSpace environment. The results showed the good behavior of the motor. Experimental verification was realized without additional LC circuit, so far. Future work can be focused on selecting the proper type of the filter, its optimal design. Also, selecting the right value of capacitor for the auxiliary phase is important. Modern control method, torque and angular speed ripple reduction, and so on, can be used.

\section{Acknowledgment}

This work was supported by projects: ITMS 26220220078 and ITMS 26210120021 co-funded from EU sources and European Regional Development Fund (ERDF).

\section{References}

[1] CHOMAT, M., LIPO, T. A.: Adjustable-Speed Single-Phase IM Drive with Reduced Number of Switches. IEEE Transactions on Industry Applications, 39(3), 819-825, 2003.

[2] BENEDICT, E. R., LIPO, T. A.: Improved PWM Modulation for a Permanent-Split Capacitor Motor. Conference Record of International IEEE-IAS Annual Meeting, Italy, 2004-2010, 2000.

[3] WU, M., LU, D. D-CH.: Active Stabilization Methods of Electric Power Systems with Constant Power Loads. A Review. Journal of Modern Power Systems and Clean Energy, 2(3), 233-243, 2014

[4] VODOVOZOV, V., LILLO, N., RAUD, Z.: Single-Phase Electric Drive for Automotive Applications. Proceedings of International Symposium on Power Electronics. Electrical Drives, Automation and Motion (SPEEDAM'14), Italy, 2014.

[5] DOBRUCKY, B., LASKODY, T., PRAZENICA, M.: A Novel Supply System for Two- Phase Induction Motor by Single Leg Matrix Converter. Elektronika ir elektrotechnika, 21(4), 13-16, 2015.

[6] ZUCKERBERGER, A., WEINSTOCK, D. ALEXANDROVITZ, A.: Single-Phase Matrix Converter. IEE Proceedings - Electric Power Applications, 144(4), 235-240, 1997. 


\section{KOMNIKCCle}

[7] JEEVANANTHAN, S., DANANJAYAN, P., MADHAVAN, R.: Novel Single-Phase to Single-Phase Cyclo-Conversion Strategies. Mathematical and Simulations Studies. International Journal of Power and Energy Systems, 27(4), 414-423, 2004.

[8] STEFANEC, P., DOBRUCKY, B.: One Leg MxC Analysis and Modelling. Proceedings of International Conference on Electrical Drives and Power Electronics (EDPE), Slovakia, 2015.

[9] LASKODY, T., DOBRUCKY, B., STEFANEC, P., PRAZENICA, M.: Comparison of a Single-Phase Induction Motor Drive Fed by VSI and MxC with Option of Speed Reduction. Proceedings of International Conference on Electrical Drives and Power Electronics (EDPE), Slovakia, 2015.

[10] KONARIK, R., DOBRUCKY, B., STEFANEC, P.: Improved Two-Phase One-Leg Matrix Converter Using L-C Filter. Proceedings of International Conference on Mechatronics, Control and Automation Engineering (ICAMM 2016), Thailand, 2016.

[11] LETTENMAINER, A., NOVOTNY, D., LIPO, T. A.: Single-Phase Induction Motor with an Electronically Controlled Capacitor. IEEE Transactions on Industry Applications, 27(1), 38-43, 1988.

[12] DANILA, A., MARgINEANU, I., CAMPEANU, R., SUCIU, C., BOIAN, I.: The Optimization of the Single/Two Phase Induction Motor Start-Up with Electronically Switched Capacitor. Proceedings of IEEE International Conference on Automation, Quality and Testing, Robotics (AQTR'08), Romania, 450 - 453, 2008.

[13] GONG, W., HU, S., SHAN, M., XU, H.: Robust Current Control Design of a Three-Phase Voltage Source Converter. Journal of Modern Power Systems and Clean Energy, 2(1), 16-22, 2014

[14] KASCAK, S., LASKODY, T., PRAZENICA, M., KONARIK, R.: Current Control Contribution to a Single-Phase Induction Motor Fed by Single-Leg VSI Inverter. Proceedings of International Conference ELEKTRO 2016, Slovakia, 172-172, 2016. 